\title{
Evaluation of Cadastral Work Done Using Total Station Instrument
}

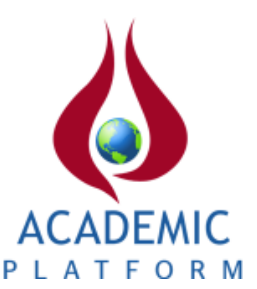

\author{
${ }^{* 1}$ Mohammed Aldelgawy \\ ${ }^{* 1}$ Faculty of Hijjawi for Engineering Technology, Civil Engineering Department, Yarmouk University, Irbid, Jordan \\ Faculty of Engineering, Civil Engineering Department, Fayoum University, Fayoum, Egypt
}

\begin{abstract}
Total station has become the main tool in most engineering work. Accordingly, evaluation of this work has gained a significant importance. A methodology to evaluate precision of cadastral work done using total station is presented here. The used technique is based on propagation of random errors of quantities measured by total station; i.e., distance and both horizontal and vertical angles. Random error in distance is produced by EDM unit integrated into total station. Whereas, random errors in horizontal and vertical angles are produced by theodolite integrated unit. Moreover, backsight process conducted in field results in addition random error in horizontal angles. This research studies how the above errors affect the resulted rectangular coordinates measured by total station for each observed point. Experiments were done using both simulated and real datasets. Results showed that the calculated errors were close to the expected errors and did not exceed the allowable ones.
\end{abstract}

Key words: Total station, random error evaluation, quality assurance, land surveying

\section{Introduction}

\subsection{General}

Since total station instrument has gained a great interest in land surveying work, the evaluation of the work performed by total station has become quite necessary. A repeated question is always raised in the field, which is "how precise is the work?" Although the question seems to be a simple one, the answer is not that simple. To precisely answer to this question, the composition of total station should be considered. Total station instrument consists of two main integrated measuring units in addition to a computer unit [11]. The first measuring unit is an electronic distance measurement (EDM) instrument. Whereas, the second measuring unit is a theodolite instrument. As a result, errors happening due to measuring by total station are errors resulted from both EDM and theodolite instruments. These resulted errors might be systematic errors or random errors.

Systematic errors are those errors that have the same value (magnitude and sign) in a series of measurements repeated under the same conditions [11]. In other words, they obey a direct mathematical relationship to calculate them. Systematic errors related to total station are classified to personal errors, atmospheric errors, and instrumental errors [9]. Personal errors are those errors such as careless centering, leveling, and aiming top target. Atmospheric errors are those errors such as errors due to wind variations or temperature differentials. Finally, instrumental errors are errors related to EDM instrument or theodolite instrument. Instrumental errors due to EDM are scale (proportional) error, index (constant) error, and cyclic error [1], [7]. While, instrumental errors of theodolite are errors related to both horizontal and vertical circles of theodolite [9].

*Corresponding Author: Mohammed Aldelgawy: Address: Faculty of Hijjawi for Engineering, Department of Civil Engineering Yarmouk University, Irbid, JORDAN. E-mail address: mas00@fayou.edu.eg, Phone: +962786876593 
On the other hand, random errors are those errors which remain after all other errors have been removed. They are beyond the control of the observer and result from the human inability of observer to make exact measurements [9]. When observing any point using total station instrument, the output quantities displayed on the total station screen are the $3 \mathrm{D}$ rectangular coordinates in east, north, and vertical directions $(E, N, Z)$ of this observed point. However, these coordinates are not observed directly. They are calculated by the computer unit integrated into the total station instrument. In order to calculate these output rectangular coordinates, a number of input observations are done by total station. The distance between the telescope of total station and the prism is observed by EDM unit embedded in total station. Both horizontal and vertical angles are observed by the embedded theodolite unit. Moreover, the north direction and the 3D rectangular coordinates of occupied (station) point, in addition to the height of both instrument and target (prism) should be known (or previously observed). They are entered manually to the total station instrument. If the input observed quantities have errors, definitely the output quantities computed from them will have errors. Evaluation of the errors in the computed output quantities as functions of the input measurements is called error propagation [6]. Accordingly, the values of the expected random errors of the output $3 \mathrm{D}$ rectangular coordinates $(E, N, Z)$ of observed point are calculated applying error propagation rules [5] on the input observed quantities for this observed point.

In this research, all systematic errors are neglected assuming that the used total station is recently well calibrated and observations are performed carefully and expertly. Accordingly, the focus will be only on the random errors which take place during observation. The mathematical formulae used to calculate the values of expected random errors of the output 3D rectangular coordinates of observed points are introduced in this research. A detailed study of the sources of random errors while measuring is presented as well. In addition, the experimental work besides the results analysis for both simulated and real datasets are illustrated. Finally, the conclusion and recommendations of the future work are introduced at the end of the research.

\subsection{Research objective}

The main objective of this research is to introduce a mathematical approach to evaluate the cadastral work performed by total station instrument. This is done by applying the error propagation rules on the input observed quantities in order to calculate the expected random errors in output 3D rectangular coordinates $(E, N, Z)$ produced by the total station for each observed point.

\section{Mathematical Approach Used for Evaluation}

\subsection{Rectangular coordinates of points observed by total station instrument:}

For any observed point, the mathematical formulae which represent the relationship between the input observations and the output 3D rectangular coordinates of this point are as follows [11]:

For horizontal (planimetric) coordinates (Figure 1):

$E=E_{O}+S \cdot \operatorname{Cos} v \cdot \operatorname{Sin} \alpha$
$N=N_{O}+S \cdot \operatorname{Cos} v \cdot \operatorname{Cos} \alpha$ 


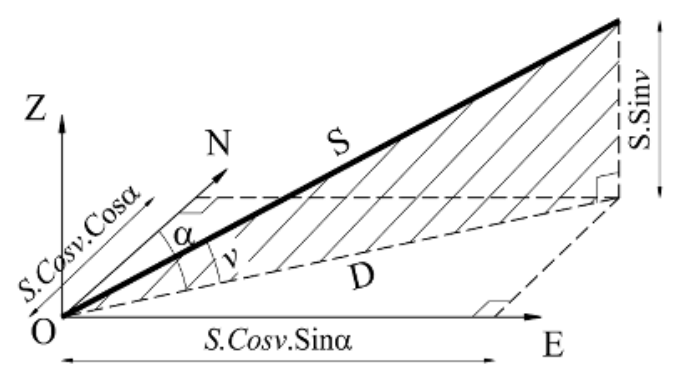

Figure 1. Horizontal (Planimetric) Coordinates of Point Observed by Total Station Instrument

Whereas, for vertical coordinate (Figure 2):

$$
Z=Z_{O}+h_{O}-h_{t}+S \cdot \operatorname{Sin} v
$$

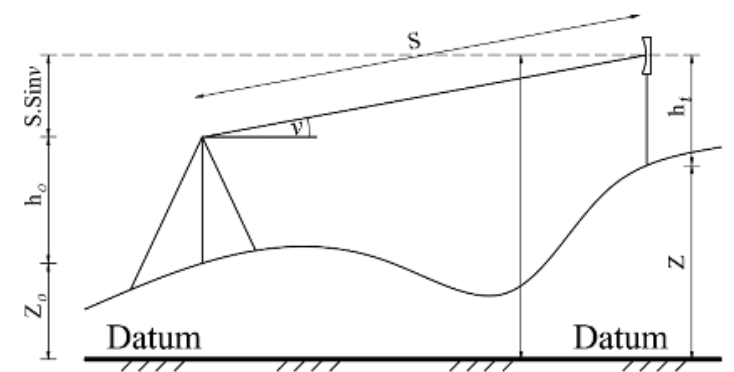

Figure 2. Vertical Coordinate of Point Observed by Total Station Instrument

\section{; Where:}

$(E, N, Z)$ and $\left(E_{O}, N_{O}, Z_{O}\right)$ are the $3 \mathrm{D}$ rectangular coordinates of both observed point and occupied (station) point in east, north, and vertical directions, respectively, $(S, \alpha, v)$ are distance between the telescope of total station and the prism, horizontal azimuth angle, and vertical angle measured by the total station instrument, respectively, $h_{o}$ is the height of total station instrument, and $h_{t}$ is the target (prism) height.

As shown in equations (1), (2), and (3), the values of output quantities $(E, N, Z)$ depends on those of the input quantities $(S, \alpha, v),\left(E_{o}, N_{o}, Z_{O}\right),\left(h_{o}, h_{t}\right)$. Some of these input quantities are directly observed; such as distance $(S)$ between telescope and prism (observed by EDM) and both horizontal angle $(\alpha)$ and vertical angle $(v)$ (observed by theodolite). Whereas, other quantities are previously observed and entered manually to total station; such as rectangular coordinates of the occupied $\operatorname{point}_{\left(E_{O}, N_{o}, Z_{o}\right)}$, height of instrument $_{\left(h_{O}\right)}$, and target (prism) height $\left(h_{t}\right)$. Applying error propagation rules on the above three equations leads to computing the values of the expected random errors of the output $3 \mathrm{D}$ rectangular coordinates of observed point(s).

Moreover, the north direction is assigned in field either directly using a compass or by making backsight. Backsight is the process of aligning the horizontal circle of total station in order to make sure the coordinate system is consistent to that of the entire project [2]. In field, backsight process is done before the observing process. This results in additional random (propagated) error in the observed horizontal angle. Consequently, after finishing backsight process, the rectangular coordinated of observed points are affected by the propagated value of the additional random error of the horizontal angle. In the following subsections the expected random error in horizontal angle due to the backsight process is presented. Afterwards, the expected random errors in the output 3D rectangular coordinates of the observed point are introduced. 


\subsection{Expected random errors in horizontal angles due to backsight:}

Backsight process is performed by providing the total station by the horizontal coordinates of the occupied (station) point $\left(E_{O}, N_{O}\right)$. In addition, the horizontal coordinates of the backsight point $\left(E_{B S}, N_{B S}\right)$ is provided to the total station instrument. Backsight point is a station point which is previously observed by total station instrument.

After setting up total station on occupied point $\left(A_{o}\right)$, the telescope of total station is aimed towards backsight point $\left(A_{B S}\right)$ in order to set the north direction [10]. Accordingly, the measured horizontal angle is affected by two sources of errors. The first error is the error due to the measured coordinates of both station point and backsight point. Whereas, the second error is the error in horizontal angle resulted from aiming the telescope of total station to the backsight point. The overall backsight error is the resultant of these two errors. The above errors in addition to their overall effect on the accuracy of the horizontal angle of the next observed point(s) are illustrated in the following subsections.

\subsubsection{Random error in backsight angle due to measured coordinates of both station point and backsight point:}

Backsight is done in order to assign the north direction. This is made by the total station by calculating the azimuth angle $(\theta)$ of the backsight line $\left(A_{O} A_{B S}\right)$ from the north direction, then setting the north direction (Figure 3).

The azimuth angle $(\theta)$ of the backsight line $\left(A_{O} A_{B S}\right)$ is calculated as follows (Figure 3):

$\theta=\operatorname{Tan}^{-1}\left[\frac{\left(E_{B S}-E_{O}\right)}{\left(N_{B S}-N_{O}\right)}\right]$

; Where:

$\left(E_{o}, N_{o}\right)$ are the horizontal (planimetric) coordinates of the occupied (station) point in both east and north directions, respectively, $\left(E_{B S}, N_{B S}\right)$ are the horizontal (planimetric) coordinates of the backsight point in both east and north directions, respectively.

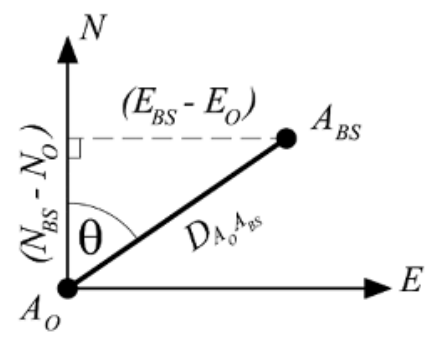

Figure 3. Top View Illustrating the Process of Backsight

As shown in equation (4), the value of the calculated azimuth angle $(\theta)$ of backsight line depends on the measured planimetric coordinates of both station point $\left(E_{O}, N_{O}\right)$ and backsight point $\left(E_{B S}, N_{B S}\right)$. Consequently, the expected $\operatorname{error}_{\left(\sigma_{\theta}\right)}$ in the calculated horizontal azimuth angle is affected by the errors in measuring planimetric coordinates of both station point and backsight. Applying the error propagation rule [5] to equation (4) to find the expected error $\left(\sigma_{\theta}\right)$ in the calculated horizontal azimuth angle leads to: $\sigma_{\theta}^{2}=\left(\partial \theta / \partial E_{O}\right)^{2} \sigma_{E_{O}}^{2}+\left(\partial \theta / \partial E_{B S}\right)^{2} \sigma_{E_{B S}}^{2}+\left(\partial \theta / \partial N_{O}\right)^{2} \sigma_{N_{O}}^{2}+\left(\partial \theta / \partial N_{B S}\right)^{2} \sigma_{N_{B S}}^{2}$

; Where:

$\sigma_{\theta}$ is the expected error in backsight angle due to measured coordinates of both station point and 
backsight point,

$\left(\sigma_{E_{o}}, \sigma_{N_{o}}\right)$ are the random errors of the coordinates of the occupied (station) point in the east and north directions, respectively,

$\left(\sigma_{E_{B S}}, \sigma_{N_{B S}}\right)$ are the random errors of the coordinates of the backsight point in the east and north directions, respectively, and

Then:

$$
\begin{aligned}
& \sigma_{\theta}^{2}=\left(\frac{-\operatorname{Cos}^{2} \theta}{\left(N_{B S}-N_{O}\right)}\right)^{2} \sigma_{E_{O}}^{2}+\left(\frac{\operatorname{Cos}^{2} \theta}{\left(N_{B S}-N_{O}\right)}\right)^{2} \sigma_{E_{B S}}^{2}+\left(\frac{\operatorname{Sin} \theta * \operatorname{Cos} \theta}{\left(N_{B S}-N_{O}\right)}\right)^{2} \sigma_{N_{O}}^{2}+\left(\frac{-\operatorname{Sin} \theta * \operatorname{Cos} \theta}{\left(N_{B S}-N_{O}\right)}\right)^{2} \sigma_{N_{B S}}^{2} \\
& \therefore \sigma_{\theta}^{2}=\frac{\operatorname{Cos}^{2} \theta}{\left(N_{B S}-N_{O}\right)^{2}}\left[\left(\sigma_{E_{O}}^{2}+\sigma_{E_{B S}}^{2}\right) * \operatorname{Cos}^{2} \theta+\left(\sigma_{N_{O}}^{2}+\sigma_{N_{B S}}^{2}\right) * \operatorname{Sin}^{2} \theta\right]
\end{aligned}
$$

But (From Figure 3):

$$
\begin{aligned}
& \operatorname{Cos} \theta=\frac{\left(N_{B S}-N_{O}\right)}{D_{A_{O} A_{B S}}} \Rightarrow \frac{\operatorname{Cos} \theta}{\left(N_{B S}-N_{O}\right)}=\frac{1}{D_{A_{O} A_{B S}}} \\
& \therefore \frac{\operatorname{Cos}^{2} \theta}{\left(N_{B S}-N_{O}\right)^{2}}=\frac{1}{D_{A_{O} A_{B S}}^{2}}
\end{aligned}
$$

Therefore:

$$
\sigma_{\theta}^{2}=\frac{1}{D_{A_{O} A_{B S}}^{2}}\left[\left(\sigma_{E_{O}}^{2}+\sigma_{E_{B S}}^{2}\right) * \operatorname{Cos}^{2} \theta+\left(\sigma_{N_{O}}^{2}+\sigma_{N_{B S}}^{2}\right) * \operatorname{Sin}^{2} \theta\right]
$$

Then:

$$
\sigma_{\theta}=\frac{1}{D_{A_{O} A_{B S}}} \sqrt{\left[\left(\sigma_{E_{O}}^{2}+\sigma_{E_{B S}}^{2}\right) * \operatorname{Cos}^{2} \theta+\left(\sigma_{N_{O}}^{2}+\sigma_{N_{B S}}^{2}\right) * \operatorname{Sin}^{2} \theta\right]}
$$

; Where:

$D_{A_{O} A_{B S}}$ is the horizontal distance between the station point $\left(A_{O}\right)$ and the backsight point $\left(A_{B S}\right)$ :

$D_{A_{O} A_{B S}}=\sqrt{\left(N_{B S}-N_{O}\right)^{2}+\left(E_{B S}-E_{O}\right)^{2}}$

\subsubsection{Random error in backsight angle resulted from aiming telescope of total station to backsight point:}

Since the process of backsight requires aiming the telescope of total station instrument to the backsight point and measuring a horizontal angle of $\left(\alpha_{\text {Instrument }}\right)$, an error in the azimuth (horizontal) angle is generated equals to the value of the accuracy of measuring horizontal angles for the used total station $\left(\sigma_{\alpha_{-} \text {Instrument }}\right)$.

\subsubsection{Overall random error in horizontal angle resulted from backsight:}

The overall value of the backsight $\operatorname{angle}\left(\alpha_{B S}\right)$ is the summation the above two $\operatorname{angles}\left(\theta, \alpha_{\text {Instrument }}\right)$; i.e.:

$\alpha_{B S}=\theta+\alpha_{\text {Instrument }}$

Then, applying error propagation rule:

$\sigma_{\alpha_{-} B S}=\sqrt{\sigma_{\theta}^{2}+\sigma_{\alpha_{-} \text {nstrument }}^{2}}$

; Where:

$\sigma_{\alpha_{-} B S}$ the error resulted from the backsight process. 


\subsubsection{Random error in horizontal angle of any point observed after finishing backsight:}

The measured horizontal angle $(\alpha)$ for each observed point is the summation of the backsight angle $\left(\alpha_{B S}\right)$ of the backsight line and the horizontal angle ${\left(\alpha_{\text {Instrument }}\right)}$ measured by the total station for each observed point; i.e.:

$\alpha=\alpha_{B S}+\alpha_{\text {Instrument }}$

Then, applying error propagation rule:

$\sigma_{\alpha}=\sqrt{\sigma_{\alpha_{-} B S}^{2}+\sigma_{\alpha_{-} \text {Instrument }}^{2}}$

\subsection{Expected random errors in rectangular coordinates of points observed using total station instrument:}

\subsubsection{Expected errors in horizontal (planimetric) coordinates of observed point:}

The horizontal coordinates $(E, N)$ of the observed point are calculated by the total station instrument (Figure 1) using equations (1) and (2). Applying the error propagation rule to equation (1), the expected error in the east coordinate $\left(\sigma_{E}\right)$ of the observed point is obtained as follows:

$\sigma_{E}^{2}=\left(\partial E / \partial E_{O}\right)^{2} \cdot \sigma_{E O}^{2}+(\partial E / \partial S)^{2} \cdot \sigma_{S}^{2}+(\partial E / \partial \alpha)^{2} \cdot \sigma_{\alpha}^{2}+(\partial E / \partial v)^{2} \cdot \sigma_{v}^{2}$

; Where:

$\sigma_{E o}$ is the error in calculating the east coordinate ${ }^{\left(E_{O}\right)}$ of the occupied (station) point,

$\sigma_{S}$ is the error in measuring the distance ${ }^{(S)}$ using the total station instrument,

$\sigma_{\alpha}$ is the error in measuring the horizontal angle ${ }^{(\alpha)}$ using the total station instrument, and

$\sigma_{v}$ is the accuracy of measuring vertical angles ${ }^{(v)}$ for the used total station instrument.

Since:

$\partial E / \partial E_{O}=1$,

$\partial E / \partial S=\operatorname{Cos} v . \operatorname{Sin} \alpha=\left(E-E_{O}\right) / S$

$\therefore \partial E / \partial S=\frac{\left(E-E_{O}\right)}{D} \cdot \operatorname{Cos} v$

; Where: $D$ is the horizontal distance between the total station (occupied point) and the prism (observed point) which can be simply obtained as follows (Figure 1):

$D=S . C O S v$

$; \partial E / \partial \alpha=S \cdot \operatorname{Cos} v \cdot \operatorname{Cos} \alpha \Rightarrow \partial E / \partial \alpha=\left(N-N_{O}\right)$,

$\partial E / \partial v=-S \cdot \operatorname{Sin} v \cdot \operatorname{Sin} \alpha=-S \cdot \operatorname{Cos} v \cdot \frac{\operatorname{Sin} v}{\operatorname{Cos} v} \cdot \operatorname{Sin} \alpha$

$=-S \cdot \operatorname{Cosv} \cdot \operatorname{Sin} \alpha \cdot \operatorname{Tan} v$

$\therefore \partial E / \partial v=-\left(E-E_{O}\right) \cdot \operatorname{Tan} v$

$\therefore \sigma_{E}^{2}=(1)^{2} \cdot \sigma_{E o}^{2}+\left(\frac{\left(E-E_{O}\right)}{D} \cdot \operatorname{Cos} v\right)^{2} \cdot \sigma_{S}^{2}+\left(N-N_{O}\right)^{2} \cdot \sigma_{\alpha}^{2}+\left(-\left(E-E_{O}\right) \cdot \operatorname{Tan} v\right)^{2} \cdot \sigma_{v}^{2}$

$\therefore \sigma_{E}=\sqrt{\sigma_{E O}^{2}+\left(\frac{\left(E-E_{O}\right)}{D} \cdot \operatorname{Cos} v\right)^{2} \cdot \sigma_{S}^{2}+\left(N-N_{O}\right)^{2} \cdot \sigma_{\alpha}^{2}+\left(\left(E-E_{O}\right) \cdot \operatorname{Tan} v\right)^{2} \cdot \sigma_{v}^{2}}$

Similarly, the expected random error in the north coordinate ${ }^{\left(\sigma_{N}\right)}$ of the observed point is obtained applying the error propagation rule to equation (2) as follows (Figure 1):

$\sigma_{N}^{2}=\left(\partial N / \partial N_{O}\right)^{2} \cdot \sigma_{N o}^{2}+(\partial N / \partial S)^{2} \cdot \sigma_{S}^{2}+(\partial N / \partial \alpha)^{2} \cdot \sigma_{\alpha}^{2}+(\partial N / \partial v)^{2} \cdot \sigma_{v}^{2}$ 
; Where:

$\sigma_{N o}$ is the error in calculating the north coordinate $\left(N_{O}\right)$ of the occupied (station) point, Since:

$$
\begin{aligned}
& \partial N / \partial N_{O}=1, \\
& \partial N / \partial S=\operatorname{Cos} v \cdot \operatorname{Cos} \alpha=\left(N-N_{O}\right) / S \\
& \therefore \partial E / \partial S=\frac{\left(N-N_{O}\right)}{D} \cdot \operatorname{Cos} v \\
& \partial N / \partial \alpha=-S \cdot \operatorname{Cos} v \cdot \operatorname{Sin} \alpha \Rightarrow \partial E / \partial \alpha=-\left(E-E_{O}\right), \\
& \partial N / \partial v=-S \cdot \operatorname{Sin} v \cdot \operatorname{Cos} \alpha=-S \cdot \operatorname{Cos} v \cdot \frac{\operatorname{Sin} v}{\operatorname{Cos} v} \cdot \operatorname{Cos} \alpha \\
& \quad=-S \cdot \operatorname{Cos} v \cdot \operatorname{Cos} \alpha \cdot \operatorname{Tan} v \\
& \therefore \partial N / \partial v=-\left(N-N_{O}\right) \cdot \operatorname{Tan} v \\
& \therefore \sigma_{N}^{2}=(1)^{2} \cdot \sigma_{N o}^{2}+\left(\frac{\left(N-N_{O}\right)}{D} \cdot \operatorname{Cos} v\right)^{2} \cdot \sigma_{S}^{2}+\left(E-E_{O}\right)^{2} \cdot \sigma_{\alpha}^{2}+\left(-\left(N-N_{O}\right) \cdot \operatorname{Tan} v\right)^{2} \cdot \sigma_{v}^{2} \\
& \therefore \sigma_{N}=\sqrt{\sigma_{N o}^{2}+\left(\frac{\left(N-N_{O}\right)}{D} \cdot \operatorname{Cos} v\right)^{2} \cdot \sigma_{S}^{2}+\left(E-E_{O}\right)^{2} \cdot \sigma_{\alpha}^{2}+\left(\left(N-N_{O}\right) \cdot \operatorname{Tan} v\right)^{2} \cdot \sigma_{v}^{2}}
\end{aligned}
$$

\subsubsection{Expected error in the vertical coordinate of observed point:}

The vertical coordinate $(Z)$ of the observed point is calculated by the total station instrument (Figure 2) using equation (3). Applying the error propagation rule to equation (3), the expected error in the vertical coordinate $\left(\sigma_{Z}\right)$ of the observed point is obtained as follows:

$\sigma_{Z}^{2}=\left(\partial Z / \partial Z_{O}\right)^{2} \cdot \sigma_{Z o}^{2}+\left(\partial Z / \partial h_{O}\right)^{2} \cdot \sigma_{h o}^{2}+\left(\partial Z / \partial h_{t}\right)^{2} \cdot \sigma_{h t}^{2}+(\partial Z / \partial S)^{2} \cdot \sigma_{S}^{2}+(\partial Z / \partial v)^{2} \cdot \sigma_{v}^{2}$

; Where:

$\sigma_{Z_{o}}$ is the error in calculating the vertical coordinate $\left(Z_{o}\right)$ of the occupied (station) point,

$\sigma_{h o}$ is the error in measuring the height of the total station instrument $\left(h_{O}\right)$, and

$\sigma_{h t}$ is the error in measuring the target (prism) height $\left(h_{t}\right)$.

Since:

$\partial Z / \partial Z_{O}=1, \partial Z / \partial h_{O}=1, \partial Z / \partial h_{t}=-1, \partial Z / \partial S=\operatorname{Sin} v, \partial Z / \partial v=S . \operatorname{Cos} v=D$

$\therefore \sigma_{Z}^{2}=(1)^{2} \cdot \sigma_{Z o}^{2}+(1)^{2} \cdot \sigma_{h o}^{2}+(-1)^{2} \cdot \sigma_{h t}^{2}+(\operatorname{Sin} v)^{2} \cdot \sigma_{S}^{2}+D^{2} \cdot \sigma_{v}^{2}$

$\therefore \sigma_{Z}=\sqrt{\sigma_{Z o}^{2}+\sigma_{h o}^{2}+\sigma_{h t}^{2}+(\operatorname{Sin} v)^{2} \cdot \sigma_{S}^{2}+D^{2} \cdot \sigma_{v}^{2}}$

\section{Experimental Work}

Experiments were done using both simulated and real datasets. The details of experiments in addition to analysis of the obtained results are illustrated in the following subsections.

\subsection{Experiments for simulated dataset:}

Experiments were conducted using a simulated dataset in order to check the validity of the used mathematical approach. Dataset consists of six blocks of buildings with a fence surrounding them (Figure 4). Moreover, the figure shows a closed pentagonal traverse (A1-A2-A3-A4-A5-A1) in addition to number of surveying points (1 to 30). Perfect (no random errors added) horizontal distances between traverse points are illustrated in the figure. The label of each point illustrated in Figure 4 
consists of two parts. The left part represents the station from which this point was observed. Whereas, the right part represents the point identification code. For instance, points A4-24 means the point identification code is 24 and it was observed from station point A4. Including observed stations and backsight points: eight points were observed from station point A1, seven points from station A2, six points from station $\mathrm{A} 3$, fourteen points from station $\mathrm{A} 4$, and four points were observed from station point A5.

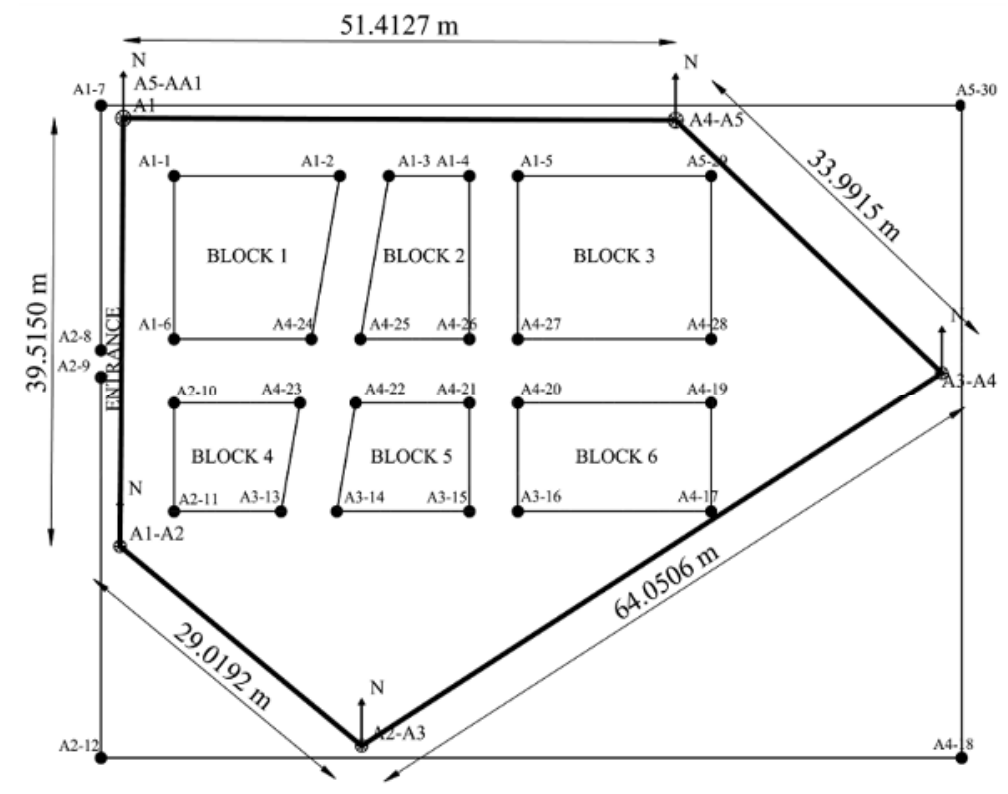

Figure 4. Top View of Simulated Dataset

As mentioned earlier, total station consists of two measuring units. The first measuring unit of total station is the EDM which is responsible for observing the distance $(S)$. While, the second measuring unit is the theodolite which is responsible for observing both horizontal angle $(\alpha)$ and vertical angle $(v)$. Accordingly, the simulated input data for each observed point are the observed distance $(S)$, horizontal angle $(\alpha)$, and vertical angle $(v)$ besides the coordinates of station $\left(E_{O}, N_{O}, Z_{O}\right)$, height of instrument $\left(h_{O}\right)$, and target height $\left(h_{t}\right)$. First, the perfect rectangular coordinates of the observed points $\left(E_{\text {Perfect }}, N_{\text {Perfect }}, Z_{\text {Perfect }}\right)$ were calculated using the above values applying equations (1), (2), and (3). Afterwards, random errors (noise) were added to the perfect input data $\left(S, \alpha, v, h_{o}, h_{t}\right)$ in order to simulate the real case as follows:

$\sigma_{S}(\mathrm{~mm})= \pm\{3 \mathrm{~mm}+3 * S(\mathrm{~km})\}, \sigma_{\alpha_{\perp} \text { Instrument }}= \pm 5^{\prime \prime}, \sigma_{v}= \pm 5^{\prime \prime}, \sigma_{h o}= \pm 10 \mathrm{~mm}$, and $\sigma_{h t}= \pm 10 \mathrm{~mm}$.

The noised rectangular coordinates of each observed point $\left(E_{\text {Noised }}, N_{\text {Noised }}, Z_{\text {Noised }}\right)$ were calculated again using the noised input data applying equations (1), (2), and (3). The difference between noised coordinates $\left(E_{\text {Noised }}, N_{\text {Noised }}, Z_{\text {Noised }}\right)$ and perfect coordinates $\left(E_{\text {Perfect }}, N_{\text {Perfect }}, Z_{\text {Perfect }}\right)$ for each observed point was calculated. Then, the root mean squares errors $\left(R M S E_{E}, R M S E_{N}, R M S E_{Z}\right)$ for these differences for points observed from each station point were calculated in the $E, N$, and $Z$-directions, respectively. Moreover, the expected errors for noised coordinates $\left(\sigma_{E}, \sigma_{N}, \sigma_{Z}\right)$ for each observed point were calculated applying error propagation rule illustrated in equations (11), (12), and (13), respectively. Again, the root mean squares errors (RMSE $\sigma_{E}, \operatorname{RMSE}_{\sigma_{N}}, \mathrm{RMSE}_{\sigma_{Z}}$ ) for the expected errors for points observed from each station point were calculated in the $E, N$, and $Z$-directions. Since random errors obey the Gaussian normal distribution curve, the value of the allowable error equals three times the expected errors in east, north, and planimetric directions, respectively [6] ; i.e.: 
Allowable error in $E$-Coordinate $=3 * \mathrm{RMSE}_{\sigma_{E}}$, Allowable error in $N$-Coordinate $=3 * \mathrm{RMSE}_{\sigma_{N}}$, and Allowable error in $Z$-Coordinate $=3 * \mathrm{RMSE} \sigma_{Z}$.

Experiment using simulated dataset was conducted in two stages. The first stage was to establish the closed traverse for the study area. While, the second stage of the experiment was to monitor all observed points (both traverse points and surveying points) lying on the study area from traverse (station) points (A1 to A5). These two stages are illustrated in the following subsections.

\subsubsection{Results for closed traverse points (stations):}

In order to establish the closed traverse shown in Figure 4, the coordinates of the first point of the traverse (A1) were assumed to be $(1000,1000,100 \mathrm{~m})$ in the east, north, and vertical directions, respectively. Then, each point (station) of the closed traverse was observed from the previous one. In other words, point (A1-A2) was observed from point (A1), point (A2-A3) was observed from point (A1-A2), and so forth. Finally, the first point of the traverse (A1) was observed again from the last point (A4-A5) and named as (A5-AA1).

The difference between the east coordinate of point (A5-AA1) and the east coordinate of start point (A1) of the traverse is called linear closure errors of the closed traverse in the east direction $\left(E_{-} L_{-}\right.$in $\left._{-} C E\right)$. on the other hand, the difference between the north coordinate of point (A5-AA1) and the north coordinate of start point (A1) of the traverse is called linear closure errors of the closed traverse in the north direction $\left(N_{-}\right.$Lin_CE). The difference in planimetric (horizontal) coordinates between the observed point (A5-AA1) and the start point (A1) represents the planimetric linear closure error (Plan_Lin_CE) of the closed traverse (Figure 5). As shown in Figure 5, the value of planimetric linear closure error of the traverse is computed as follows:

$$
\text { Plan_Lin_CE }=\sqrt{\left(E_{-} \text {Lin_CE }\right)^{2}+\left(N_{-} \text {Lin } C E\right)^{2}} \ldots \ldots \ldots \text { (14) }
$$

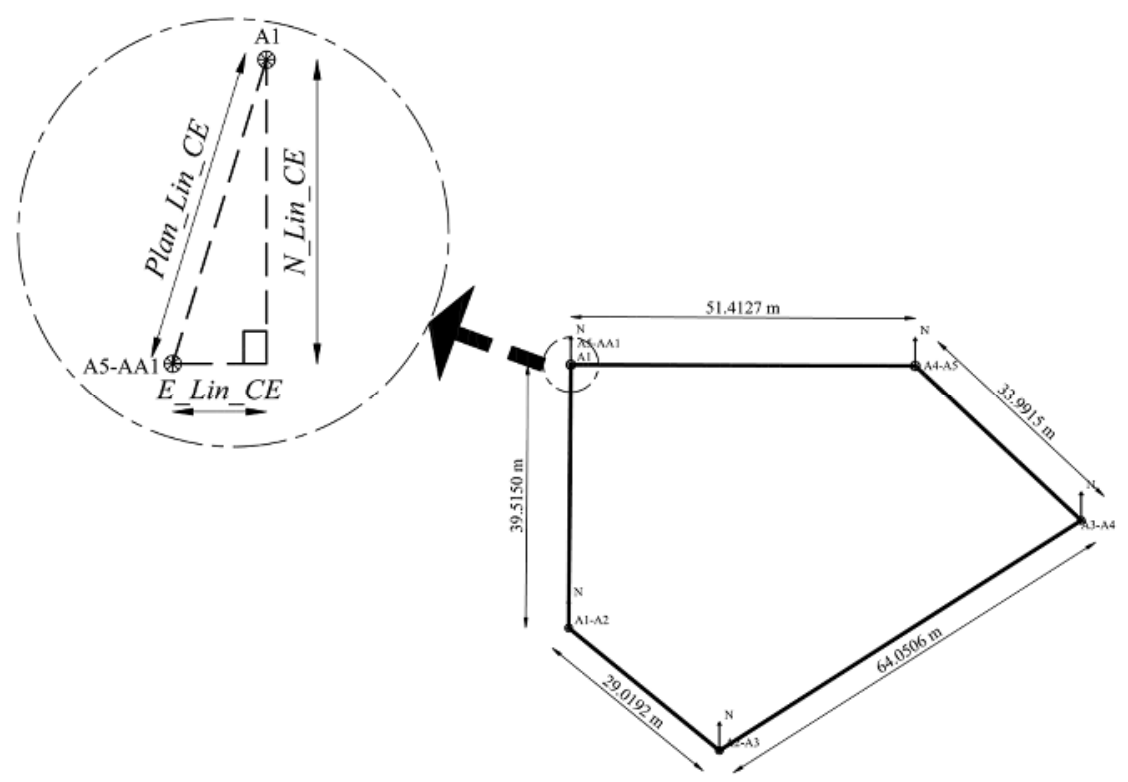

Figure 5. Linear Closure Error of Closed Traverse for Simulated Dataset

Table 1 and Table 2 show results for the closed traverse. Table 1 presents the closed traverse planimetric coordinates $(E, N)$ in addition to expected errors $\left(\sigma_{E}, \sigma_{N}\right)$ for these coordinates. Furthermore, Table 2 illustrates the linear closure error of the traverse. The first column of Table 2 represents the linear closure 
errors in the east, north, and planimetric directions, respectively. Whereas, the second column of the same table represents the expected closure errors in the east, north, and planimetric directions, respectively. Finally, the values of the allowable closure errors of the traverse in the east, north, and planimetric directions, respectively, are illustrated in the third column. It can be inferred from Table 2 that the values of linear closure errors were close to the expected ones. In addition, these values were less than the allowable values of linear closure errors.

Table 1. Expected Error for Planimetric Coordinates of Closed Traverse Points for Simulated Dataset

\begin{tabular}{cccccc}
\hline $\begin{array}{c}\text { Backsight } \\
\text { Point }\end{array}$ & $\begin{array}{c}\text { Station } \\
\text { Point }\end{array}$ & $E(m)$ & $N(m)$ & $\sigma_{E}(\mathrm{~mm})$ & $\sigma_{N}(\mathrm{~mm})$ \\
\hline NONE & A1 & 1000.0000 & 1000.0000 & 0.0 & 0.0 \\
A1 & A1-A2 & 999.6899 & 960.4894 & 1.0 & 3.1 \\
A1-A2 & A2-A3 & 1022.1840 & 942.1605 & 2.7 & 3.8 \\
A2-A3 & A3-A4 & 1076.2112 & 976.5572 & 6.4 & 9.1 \\
A3-A4 & A4-A5 & 1051.4085 & 999.8049 & 7.6 & 10.0 \\
A4-A5 & A5-AA1 & 999.9930 & 999.9772 & 8.2 & 20.7 \\
\hline
\end{tabular}

Table 2. Planimetric Linear Closure Error of Closed Traverse for Simulated Dataset

\begin{tabular}{cccc}
\hline Direction & $\begin{array}{c}\text { Linear Closure Error } \\
(\mathrm{mm})\end{array}$ & $\sigma_{A 5-A A 1}(\mathrm{~mm})$ & $\begin{array}{c}\text { Allowable Closure Error } \\
(\mathrm{mm}) \\
\left(3^{*} \sigma_{A 5-A A 1}\right)\end{array}$ \\
\hline East $(E)$ & -7.0 & 8.2 & 24.6 \\
North $(N)$ & -22.8 & 20.7 & 62.1 \\
Planimetric & 23.9 & 22.3 & 66.9 \\
\hline
\end{tabular}

\subsubsection{Results for all observed points:}

In this part of research, results for all points observed from each station point (A1 to A5) are introduced. A comparison between root mean squares errors for differences in coordinates $\left(R M S E_{E}, R M S E_{N}, R M S E_{Z}\right)$ and root mean squares errors for expected errors (RMSE $\sigma_{E}, \operatorname{RMSE}_{\sigma_{N}}, \operatorname{RMSE}_{\sigma_{Z}}$ ) is presented in Table 3 and Figures 6, 7, and 8. Whereas, a comparison between root mean squares errors for differences in coordinates $\left(R M S E_{E}, R M S E_{N}, R M S E_{Z}\right)$ and the allowable random errors in $E, N, Z$-directions is illustrated in Table 4 and Figures 6, 7, and 8.

Table 3. Comparison between Root Mean Squares Errors for Coordinates of Observed Points and Their Expected Errors for Simulated Dataset

\begin{tabular}{cccccccc}
\hline & & \multicolumn{2}{c}{ E-Direction } & \multicolumn{2}{c}{ N-Direction } & \multicolumn{2}{c}{ Z-Direction } \\
\cline { 3 - 7 } $\begin{array}{c}\text { Backsight } \\
\text { Point }\end{array}$ & $\begin{array}{c}\text { Station } \\
\text { Point }\end{array}$ & $\begin{array}{c}R M S E_{E} \\
(\mathrm{~mm})\end{array}$ & $\begin{array}{c}\text { RMSE } \sigma_{E} \\
(\mathrm{~mm})\end{array}$ & $\begin{array}{c}R M S E_{N} \\
(\mathrm{~mm})\end{array}$ & $\begin{array}{c}\text { RMSE } \\
\sigma_{N} \\
(\mathrm{~mm})\end{array}$ & $\begin{array}{c}R M S E_{Z} \\
(\mathrm{~mm})\end{array}$ & $\begin{array}{c}\text { RMSE } \sigma_{Z} \\
(\mathrm{~mm})\end{array}$ \\
\hline NONE & $\mathrm{A} 1$ & 2.5 & 2.5 & 1.9 & 1.9 & 18.4 & 14.2 \\
$\mathrm{~A} 1$ & $\mathrm{~A} 1-\mathrm{A} 2$ & 1.4 & 1.9 & 4.1 & 4.1 & 11.1 & 20.0 \\
$\mathrm{~A} 1-\mathrm{A} 2$ & $\mathrm{~A} 2-\mathrm{A} 3$ & 3.2 & 4.8 & 7.2 & 5.9 & 11.5 & 24.6 \\
$\mathrm{~A} 2-\mathrm{A} 3$ & $\mathrm{~A} 3-\mathrm{A} 4$ & 4.0 & 7.4 & 8.3 & 11.1 & 18.5 & 28.4
\end{tabular}



A3-A4
A4-A5
5.7
9.1
12.1
15.1
25.4
31.7

Table 4. Comparison between Root Mean Squares Errors for Coordinates of Observed Points and Their Allowable Errors for Simulated Dataset

\begin{tabular}{|c|c|c|c|c|c|c|c|}
\hline \multirow{4}{*}{$\begin{array}{l}\text { Backsight } \\
\text { Point }\end{array}$} & \multirow{4}{*}{$\begin{array}{l}\text { Station } \\
\text { Point }\end{array}$} & \multicolumn{2}{|c|}{ E-Direction } & \multicolumn{2}{|c|}{ N-Direction } & \multicolumn{2}{|c|}{ Z-Direction } \\
\hline & & & (Allowable & & (Allowable & & (Allowable \\
\hline & & $R M S E_{E}$ & Error) $=$ & $R M S E_{N}$ & Error) $=$ & $R M S E_{Z}$ & Error) $=$ \\
\hline & & $(m m)^{L}$ & $\begin{array}{c}3 * \operatorname{RMSE} \sigma_{E} \\
(\mathrm{~mm})\end{array}$ & $(\mathrm{mm})^{N}$ & $\begin{array}{c}3 * \operatorname{RMSE} \sigma_{N} \\
(\mathrm{~mm})\end{array}$ & $(\mathrm{mm})$ & $\begin{array}{c}3 * \operatorname{RMSE} \sigma_{Z} \\
(\mathrm{~mm})\end{array}$ \\
\hline NONE & A1 & 2.5 & 7.5 & 1.9 & 5.7 & 18.4 & 42.6 \\
\hline A1 & $\mathrm{A} 1-\mathrm{A} 2$ & 1.4 & 5.7 & 4.1 & 12.3 & 11.1 & 60 \\
\hline $\mathrm{A} 1-\mathrm{A} 2$ & $\mathrm{~A} 2-\mathrm{A} 3$ & 3.2 & 14.4 & 7.2 & 17.7 & 11.5 & 73.8 \\
\hline $\mathrm{A} 2-\mathrm{A} 3$ & A3-A4 & 4.0 & 25.8 & 8.3 & 36.6 & 18.5 & 85.2 \\
\hline $\mathrm{A} 3-\mathrm{A} 4$ & A4-A5 & 5.7 & 27.3 & 12.1 & 45.3 & 25.4 & 95.1 \\
\hline
\end{tabular}

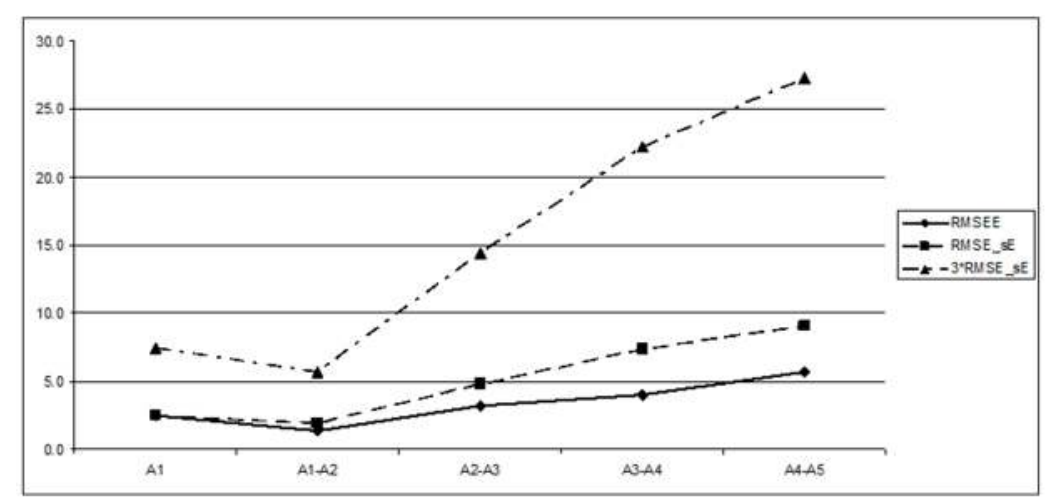

Figure 6. Results of Observed points in E-Direction for Simulated Dataset

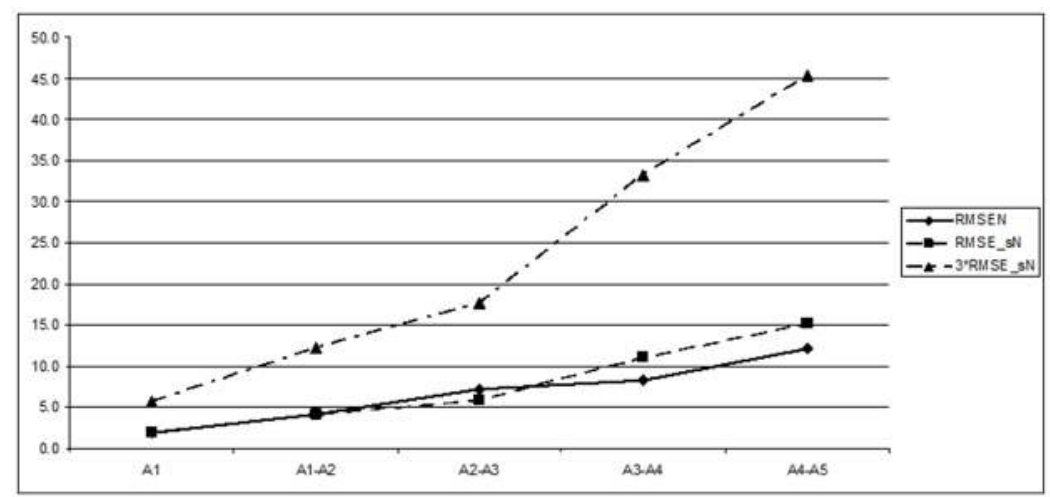

Figure 7. Results of Observed points in N-Direction for Simulated Dataset

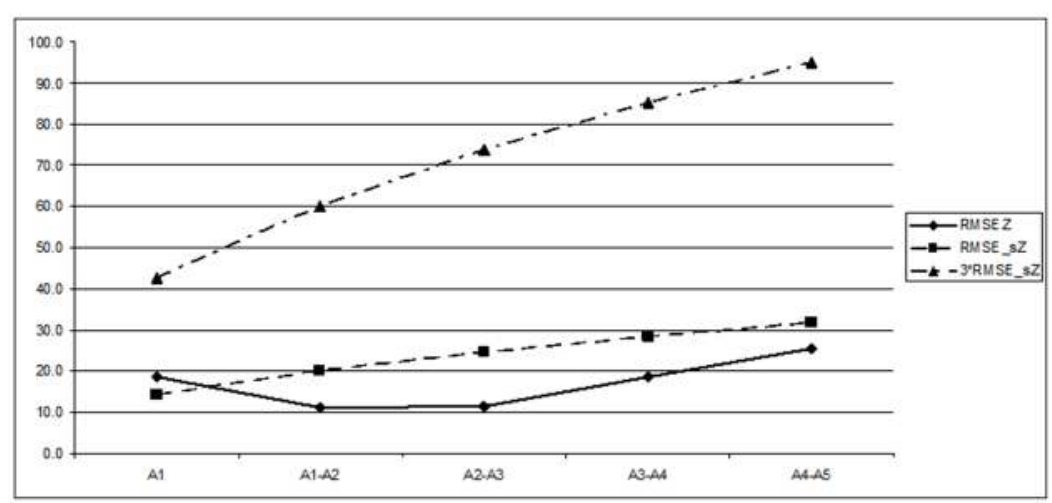

Figure 8. Results of Observed points in Z-Direction for Simulated Dataset 
The above tables and figures show that the values of differences between noised coordinates and perfect coordinates were around those values of the expected errors. In all cases, these differences did not exceed the allowable values.

\subsection{Experiments for real dataset:}

In this part of research, experiment was conducted using a real dataset. Experiment was done using a SOKKIA Series 10K SET210K total station instrument. According to the calibration report of total station instrument, the values of accuracy of measured raw data $(S, \alpha, v)$ were taken as follows: $\sigma_{S}(\mathrm{~mm})= \pm\{3 \mathrm{~mm}+3 * S(\mathrm{~km})\}, \sigma_{\alpha_{-} \text {Instrument }}= \pm 5^{\prime \prime}$, and $\sigma_{v}= \pm 5^{\prime \prime}$. In addition, the accuracy of measuring the height of instrument was taken as $10 \mathrm{~mm}$. Whereas, the accuracy of measuring the target (prism) height was taken as $\pm 10 \mathrm{~mm}$.

The surveying project was some area in The 6th of October city, Egypt. A Google Earth image for the project area is illustrated in Figure 9. The closed traverse work was done first. Then, other points of the project were observed. The focus here was on the closed traverse work. In other words, the objective of experiment was to evaluate the value of linear closure error of the heptagonal closed traverse (A1-A2A3-A4-A5-A6-A7-A1) shown in Figure 10. The measured horizontal distances between traverse points are illustrated in the same figure. The label of each point illustrated in Figure 10 consists of two parts. The left part represents the station from which this point was observed. Whereas, the right part represents the point identification code.

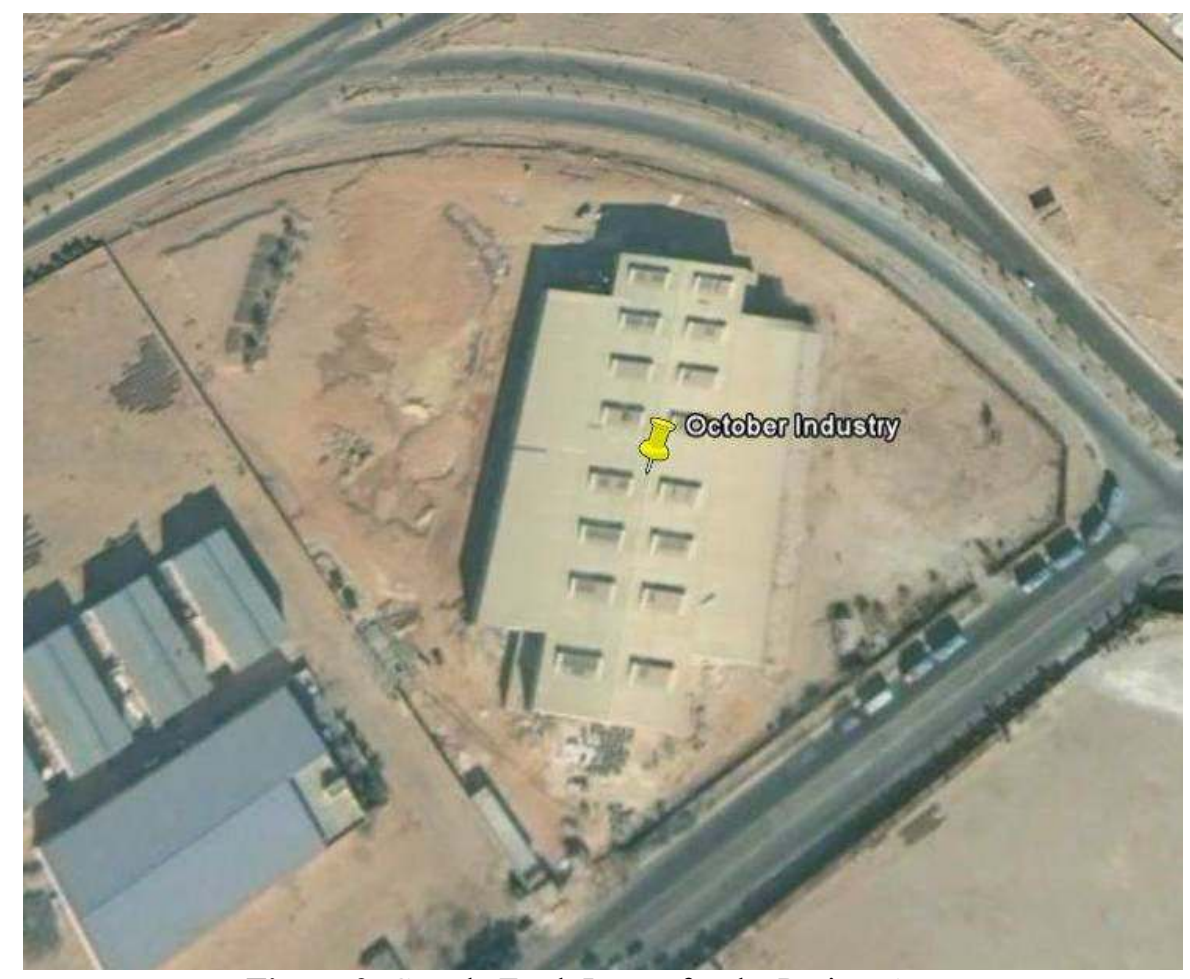

Figure 9. Google Earth Image for the Project Area 


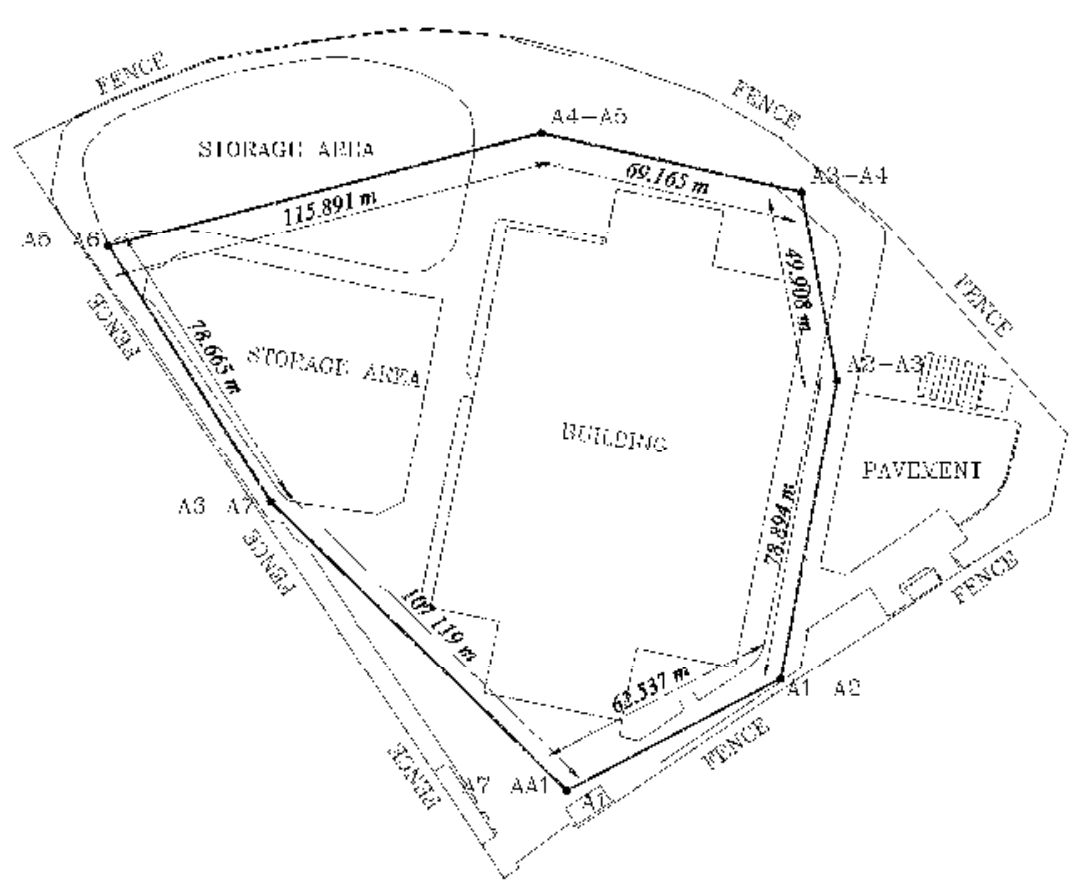

Figure 10. Top View of Real Dataset

The coordinates of the first point of the traverse (A1) were assumed to be $(1000,1000,100 \mathrm{~m})$ in the east, north, and vertical directions, respectively. Then, as done in experiment using simulated dataset, the closed traverse was established by observing each point (station) of traverse from the previous one. Finally, the first point of the traverse (A1) was observed again from the last point (A6-A7) and named as (A7-AA1). The difference in horizontal (planimetric) coordinates between the observed point (A7-AA1) and the original point (A1) was considered as the linear closure error of the closed traverse.

Results of the linear closure error of the closed traverse are illustrated in Table 5 and Table 6 . Table 5 illustrates the closed traverse planimetric coordinates $(E, N)$ besides the expected errors $\left(\sigma_{E}, \sigma_{N}\right)$ for these coordinates. The values of expected errors $\left(\sigma_{E}, \sigma_{N}\right)$ were calculated applying equations (11) and (12) using the measured raw data observed by total station with their accuracies stated in the calibration report. The first column in Table 6 represents the linear closure errors of the closed traverse in east, north, and planimetric directions, respectively. The second and third columns in the same table represent the expected closure errors and allowable closure errors of the traverse in east, north, and planimetric directions, respectively. It can be concluded from Table 6 that the values of linear closure errors are close to the expected errors and did not exceed the allowable errors.

Table 5. Expected Error for Planimetric Coordinates of Closed Traverse Points for Real Dataset

\begin{tabular}{cccccc}
\hline $\begin{array}{c}\text { Backsight } \\
\text { Point }\end{array}$ & Station Point & $E(m)$ & $N(m)$ & $\sigma_{E}(m m)$ & $\sigma_{N}(m m)$ \\
\hline NONE & A1 & 1000.000 & 1000.000 & 0.0 & 0.0 \\
A1 & A1-A2 & 1055.486 & 1028.849 & 2.9 & 2.0 \\
A1-A2 & A2-A3 & 1070.032 & 1106.390 & 4.8 & 3.8 \\
A2-A3 & A3-A4 & 1060.805 & 1155.438 & 6.2 & 5.0 \\
A3-A4 & A4-A5 & 993.356 & 1170.748 & 7.4 & 12.0 \\
A4-A5 & A5-A6 & 881.272 & 1141.287 & 9.8 & 24.3 \\
A5-A6 & A6-A7 & 923.332 & 1074.810 & 18.2 & 26.3 \\
A6-A7 & A7-AA1 & 999.975 & 1000.028 & 30.9 & 36.6 \\
\hline
\end{tabular}


Table 6. Linear Closure Error of Closed Traverse for Real Dataset

\begin{tabular}{cccc}
\hline Direction & Linear Closure Error $(\mathrm{mm})$ & $\sigma_{A 5-A A 1}(\mathrm{~mm})$ & $\begin{array}{c}\text { Allowable Closure Error }(\mathrm{mm}) \\
\left(3 * \sigma_{A 5-A A 1}\right)\end{array}$ \\
\hline East $(E)$ & -25.0 & 30.9 & 92.7 \\
North $(N)$ & 28.0 & 36.6 & 109.8 \\
Planimetric & 37.5 & 47.9 & 143.7 \\
\hline
\end{tabular}

\section{Conclusion and Recommendations}

This paper presented a mathematical approach to evaluate the precision of the coordinates of points observed by total station instrument. First, the used mathematical model, which depends on the error propagation rule, was introduced. The effect of backsight process on the accuracy of the measured horizontal angle was taken into consideration in the proposed approach. Then, the results were evaluated using both simulated and real datasets. Experiments using simulated dataset were conducted to evaluate the linear closure error of the established closed traverse in addition to the errors of rectangular coordinates for all observed points. On the other hand, experiment using real dataset was conducted to evaluate the linear closure error of the established closed traverse of some real project. The experimental results of both simulated and real datasets showed that the used approach provided a powerful and reliable tool to evaluate the cadastral work done by total station instrument. Results showed that the calculated errors were close to the expected errors. Moreover, the values of these calculated errors did not exceed the values of the allowable errors.

Future researches will focus on the study of the effect of the geometry of traverse interior angles on the expected errors. In addition, the method of establishing the closed traverse (observing coordinates of points, as done in this research, or observing distances and interior angle of traverse) will be studied. Furthermore, the used mathematical model will be developed to be applied on observing settlement of buildings. Finally, slope stability of road sides will be investigated using total instrument.

\section{Acknowledgement}

The project presented in this article is supported by Fayoum University and Yarmouk University.

\section{References}

[1] Baykal, O., Tari, E., Coskun, Z., and Erden, T. Accuracy of Point Layout with Polar Coordinates. ASCE, Journal of Surveying Engineering, Volume 131, Issue 3 (87 - 93), 2005.

[2] Kananagh, B. and Mastin, T. Surveying Principles and Applications. 9th Edition, Pearson, USA, 2014.

[3] Mao, J. M. and Nindl D. Surveying Reflectors -White Paper: Characteristics and Influence. Leica Geosystem AG, Heerburgg, Switzerland, 2009. 
[4] Martin, D. and Gatta G. Calibration of Total Station Instrument at the ESRF. Shaping the Change, XXIII FIG Congress, Munich, Germany, 2006.

[5] Mikhail, E. M. and Ackermann F. E. Observations and Least Squares. 2nd Edition, University Press of America, USA, 1982.

[6] Mikhail, E. M. and Gracie, G. Analysis \& Adjustment of Survey Measurements. 2nd Edition, Van Nostrand Reinhold Co., USA, 1981.

[7] Office of the Surveyor-General Victoria. EDM Calibration Handbook. 16th Edition, Land Use Victoria, Department of Environment, Land, Water and Planning, Melbourne, Australia, 2017.

[8] RICS Guidance Note. EDM Calibration. 2nd Edition, Royal Institution of Chartered Surveyors (RICS), UK, 2007.

[9] Schofield, W. and Beach, M. Engineering Surveying. 6th Edition, Elsevier, UK, 2007.

[10] Sokkia. Series 10 Set210 Electronic Total Station Operator's Manual. 4th Edition, Sokkia Co., Ltd., Japan, 2001.

[11] Uren, J. and Price, B. Surveying for Engineers. 5th Edition, Palgrave Macmillan, UK, 2010. 